\title{
Oral Piercing: Practice or Prejudice?
}

\section{Dipayan D*}

BDS, Department of Public Health Dentistry, Tamil Nadu Government Dental College and Hospital, India

*Corresponding author: Dipayan D, BDS, Tamil Nadu Government Dental College and

\section{Editorial}

Volume 3 Issue 1

Received Date: March 24, 2018

Published Date: March 28, 2018

DOI: 10.23880 /oajds- 16000170

Hospital, Tamil Nadu, India, 600 003, Tel: 7358565184; Email: datta.dipayan2@gmail.com

\section{Editorial}

From the dawn of civilization human beings were seen to decorate their bodies with different kinds of ornaments, be it a piece of shell, stone, bone or metal. Jewellery became a form of adornment, sometimes for protection from evil spirits or sometimes for expressing the social status. People from different cultures in different places of the world wear jewellery in various parts of their bodies according to their traditions and beliefs. Many of these practices have turned into fashion modern times. In last two decades, dental jewellery by means of oral piercing got notable attention in many developed and developing countries. Soft tissues in relation to the oral cavity such as lips, tongue, buccal mucosa are pierced and jewellery (usually made of hypoallergenic metals like gold, titanium etc.) of different shapes like stud, barbell, ring etc. are placed. While many people perform oral piercings to look trendy, numerous studies and case reports have established the fact that oral piercings can result in a wide range of oral and systemic complications.

The most common sequel of oral piercing is bleeding (especially from tongue for being a highly vascular organ). Apart from this, painful ulcerations followed by severe inflammations have also been frequently reported. Oral piercing can lead to infections caused by beta-haemolytic Streptococcus, Staphylococcus aureus, Pseudomonas aeruginosa etc. resulting in bacteraemia, septic shock and life threatening conditions like Ludwigs angina. Unsterile materials can be potential sources of Hepatitis Virus B and C, Herpes Simplex Virus, Epstein-Barr virus and Candida albicans. Continuous movement of the jewellery can cause tissue overgrowth as well as gingival recession. People with oral jewellery have tendency to play with them by pushing them towards the teeth. The frequent contact between the teeth and the hard materials causes loss of enamel and dentin, abrasions, fractures in restorations and crowns.

When a patient with such oral piercing comes to a dental clinic, it always becomes difficult for the dentist to get proper access to his/her oral cavity as the objects often create obstructions. Even if they are not removed, they create radiopaque areas in radiographs resulting in hindrance to diagnosis. Dentists commonly encounter patients with various forms of oral piercing or oral jewellery who are particularly younger adults. To reduce risks of future complication after piercing procedures the individuals should maintain a standard oral hygiene regimen including twice-daily tooth-brushing with a softbristle toothbrush, regular use of floss and use of alcoholfree mouthrinse even after the healing period. All forms of intraoral or perioral jewellery should essentially be removed before any oral diagnostic and treatment procedure.

Though the increasing demand for dental jewellery is seen in recent days among young adult population, the awareness about their effects on oral health is comparatively low. Patients with oral and perioral piercing are always in risk of oral as well as systemic adverse effect with transmission of infectious diseases. Such patients should be followed up on regular basis. Individuals with dental jewellery should frequently go for dental check-ups so that exhaustive oral examination can detect any adverse outcome at initial stage and prevent its progression through proper treatment. 